\title{
A COMPETITIVIDADE DAS EXPORTAÇÕES DE CARNE SUÍNA: OS CASOS DO BRASIL E DOS ESTADOS UNIDOS ${ }^{1}$
}

\author{
Tiane Alves Rocha Gastardelo ${ }^{2}$, Laércio Juarez Melz ${ }^{3}$, Pascoal José Marion Filho ${ }^{4}$

\section{RESUMO} \\ Este trabalho tem o objetivo de analisar a evolução da competitividade das exportações de carne \\ suína do Brasil e dos Estados Unidos, através da aplicação do modelo Constant Market Share \\ (CMS), no período de 1990 a 2014, incluindo os efeitos do comércio mundial, destino e \\ competitividade. Cinco subperíodos foram analisados: 1990-1993; 1994-1998; 1999-2002; \\ 2003-2008; 2009-2014. Os resultados apontaram que as exportações brasileiras cresceram a \\ taxas mais elevadas que as taxas mundiais. No primeiro e terceiro subperíodos, a \\ competitividade foi responsável pelo crescimento das exportações. No segundo subperíodo, o \\ aumento das importações nos destinos da carne nacional foi o responsável pelo crescimento. \\ No quarto e quinto subperíodo, a competitividade foi responsável pela estagnação das \\ exportações. Os Estados Unidos também apresentaram taxas de crescimento positivas em todos \\ os subperíodos, sendo a competitividade o maior responsável pelo bom desempenho. Ambos \\ os países apresentam fragilidades relacionadas a sanidade animal e custo dos insumos.
}

Palavras chave: Constant Market Share, suinocultura, comércio exterior.

\section{THE COMPETITIVENESS OF PORK EXPORTS: THE CASES OF BRAZIL AND UNITED STATES}

\begin{abstract}
This paper has the objective to analyze the evolution of the competitiveness of pork exports from Brazil and United States, by applying the Constant Market Share Model (CMS), from 1990 to 2014, including the effects of world trade, destination and competitiveness. Five subperiods were analyzed: 1990-1993; 1994-1998; 1999-2002; 2003-2008; 2009-2014. The results showed that Brazilian exports grew at higher rates than the global rates. In the first and third sub-period, competitiveness was responsible for the growth of exports. In the second subperiod, the increase in imports of the destiny for national meat was responsible for the growth. In the fourth and fifth sub-period, competitiveness was responsible for the stagnation of exports. The United States also showed growth rates in all sub-periods, competitiveness being largely responsible for the good performance. Both countries have weaknesses related to animal and cost of inputs.
\end{abstract}

Keywords: Constant Market Share, swine production, international trade.

\footnotetext{
${ }^{1}$ Trabalho realizado com apoio financeiro da FAPEMAT, aprovado no CONBREPRO 2015

${ }^{2}$ Mestra em Administração - Universidade Federal de Santa Maria - UFSM

${ }^{3}$ Universidade do Estado de Mato Grosso (UNEMAT). Bolsita FAPEMAT

${ }^{4}$ Doutor em Economia Aplicada - Professor do Programa de Pós-Graduação em Administração (UFSM)

Volume 5, Número $9 \quad$ Revista UNEMAT de Contabilidade

Jan./Jul. 2016

ISSN: $2316-8072$
} 


\section{INTRODUÇÃO}

Ao analisar o cenário mundial de carnes observa-se que as mais consumidas são, respectivamente, suínos, aves e bovinos. Em 2014 foram consumidas no mundo 109.954 mil toneladas de suínos, 84.668 mil toneladas de frango e 57.629 mil toneladas de bovinos. Sendo os principais exportadores de carne suína os Estados Unidos, a União Europeia, o Canadá e o Brasil; de frango, o Brasil, os Estados Unidos, a União Europeia e a Tailândia; de carne bovina, a Índia, o Brasil, a Austrália e os Estados Unidos (USDA, 2015).

Entre os exportadores, os únicos países que fazem parte do grupo dos quatro maiores nas três principais carnes são o Brasil e os Estados Unidos. Na carne suína o Brasil é o quarto maior desde o ano 2000. Neste mesmo ano os Estados Unidos foram o terceiro maior, e atualmente, são o maior exportador (USDA, 2015). A partir disso, o objetivo deste trabalho foi analisar a evolução competitividade da carne suína brasileira e estadunidense no mercado internacional, no período de 1990 a 2014, através da aplicação do método Constant Market Share (CMS), onde é possível decompor as fontes de crescimento das exportações em três efeitos: comércio mundial, destino e competitividade. Justifica-se a escolha, pela representatividade da carne suína, dos Estados Unidos e do Brasil no comércio internacional.

$\mathrm{O}$ artigo está estruturado em cinco seções incluindo esta introdução. Na segunda seção são apresentados os maiores exportadores mundiais de carne suína. Na terceira, é apresentada a metodologia. Na quarta seção são apresentados e discutidos os resultados encontrados. A quinta e última seção apresenta as considerações finais sobre o trabalho.

\section{EVOLUÇÃO DA SUINOCULTURA MUNDIAL}

Com o intuito de mostrar as mudanças nos players da suinocultura mundial o Quadro 1 apresenta em ordem decrescente os oito maiores exportadores e as suas respectivas participações no comércio internacional, em alguns pontos do tempo (1990, 1995, 2000, 2005, 2010 e 2014). 
Quadro 1 - Principais exportadores mundiais de carne suína $(1990,1995,2000$, 2005, 2010, 2014)

\begin{tabular}{|c|c|c|c|c|c|c|}
\hline & 1990 & 1995 & 2000 & 2005 & 2010 & 2014 \\
\hline 1 & $\begin{array}{c}\text { Holanda } \\
1056 \text { mil t } \\
23 \% \\
\end{array}$ & $\begin{array}{c}\text { União Europeia } \\
\begin{array}{c}772 \text { mil t } \\
34,16 \%\end{array} \\
\end{array}$ & $\begin{array}{c}\text { União Europeia } \\
\begin{array}{c}1311 \mathrm{mil} \mathrm{t} \\
42 \%\end{array} \\
\end{array}$ & $\begin{array}{c}\text { Estados Unidos } \\
1209 \text { mil t } \\
24 \%\end{array}$ & $\begin{array}{c}\text { Estados Unidos } \\
1915 \text { mil t } \\
32 \% \\
\end{array}$ & $\begin{array}{c}\text { Estados Unidos } \\
2204 \text { mil t } \\
32 \% \\
\end{array}$ \\
\hline 2 & $\begin{array}{c}\text { Dinamarca } \\
873 \text { mil t } \\
19 \% \\
\end{array}$ & $\begin{array}{c}\text { Taiwan } \\
381 \text { mil t } \\
17 \%\end{array}$ & $\begin{array}{c}\text { Canadá } \\
660 \text { mil t } \\
21 \%\end{array}$ & $\begin{array}{c}\text { União Europeia } \\
1091 \mathrm{mil} \mathrm{t} \\
22 \% \\
\end{array}$ & $\begin{array}{c}\text { União Europeia } \\
1706 \mathrm{mil} \mathrm{t} \\
28 \% \\
\end{array}$ & $\begin{array}{c}\text { União Europeia } \\
\begin{array}{c}2117 \text { mil t } \\
31 \%\end{array} \\
\end{array}$ \\
\hline 3 & $\begin{array}{c}\text { Bélgica } \\
359 \text { mil t } \\
8 \% \\
\end{array}$ & $\begin{array}{c}\text { Canadá } \\
366 \text { mil t } \\
16 \%\end{array}$ & $\begin{array}{c}\text { Estados Unidos } \\
584 \text { mil t } \\
19 \% \\
\end{array}$ & $\begin{array}{c}\text { Canadá } \\
1084 \text { mil t } \\
22 \%\end{array}$ & $\begin{array}{c}\text { Canadá } \\
1159 \text { mil t } \\
19 \% \\
\end{array}$ & $\begin{array}{c}\text { Canadá } \\
1219 \text { mil t } \\
18 \% \\
\end{array}$ \\
\hline 4 & $\begin{array}{c}\text { Alemanha } \\
347 \text { mil t } \\
8 \%\end{array}$ & $\begin{array}{c}\text { Estados Unidos } \\
357 \text { mil t } \\
16 \% \\
\end{array}$ & $\begin{array}{c}\text { Brasil } \\
162 \text { mil t } \\
5 \%\end{array}$ & $\begin{array}{c}\text { Brasil } \\
761 \mathrm{mil} \mathrm{t} \\
15 \% \\
\end{array}$ & $\begin{array}{c}\text { Brasil } \\
619 \text { mil t } \\
10 \% \\
\end{array}$ & $\begin{array}{c}\text { Brasil } \\
556 \text { mil t } \\
8 \%\end{array}$ \\
\hline 5 & $\begin{array}{c}\text { Canadá } \\
314 \text { mil t } \\
7 \% \\
\end{array}$ & $\begin{array}{c}\text { China/ Polônia* } \\
105 \text { mil t } \\
5 \% \\
\end{array}$ & $\begin{array}{c}\text { China } \\
144 \text { mil t } \\
5 \% \\
\end{array}$ & $\begin{array}{c}\text { China } \\
502 \text { mil t } \\
10 \% \\
\end{array}$ & $\begin{array}{c}\text { China } \\
278 \text { mil t } \\
5 \% \\
\end{array}$ & $\begin{array}{c}\text { China } \\
277 \text { mil t } \\
4 \%\end{array}$ \\
\hline 6 & $\begin{array}{c}\text { China } \\
235 \text { mil t } \\
5 \%\end{array}$ & $\begin{array}{c}\text { Hungria } \\
83 \text { mil t } \\
4 \%\end{array}$ & $\begin{array}{c}\text { México } \\
59 \text { mil t } \\
2 \%\end{array}$ & $\begin{array}{c}\text { Chile } \\
128 \text { mil t } \\
3 \%\end{array}$ & $\begin{array}{c}\text { Chile } \\
130 \text { mil t } \\
2 \%\end{array}$ & $\begin{array}{c}\text { Chile } \\
163 \text { mil t } \\
2 \%\end{array}$ \\
\hline 7 & $\begin{array}{c}\text { Taiwan } \\
225 \text { mil t } \\
5 \%\end{array}$ & $\begin{array}{c}\text { Brasil } \\
46 \text { mil t } \\
2 \%\end{array}$ & $\begin{array}{c}\text { Austrália } \\
52 \text { mil t } \\
2 \%\end{array}$ & $\begin{array}{c}\text { México } \\
59 \text { mil t } \\
1 \%\end{array}$ & $\begin{array}{c}\text { México } \\
78 \text { mil t } \\
1 \%\end{array}$ & $\begin{array}{l}\text { México } \\
117 \text { mil t } \\
2 \%\end{array}$ \\
\hline 8 & $\begin{array}{c}\text { Hungria } \\
210 \text { mil t } \\
5 \%\end{array}$ & $\begin{array}{c}\text { Cazaquistão } \\
45 \text { mil t } \\
2 \%\end{array}$ & $\begin{array}{c}\text { Coréia do Sul } \\
32 \text { mil t } \\
1 \%\end{array}$ & $\begin{array}{c}\text { Austrália } \\
56 \text { mil t } \\
1 \%\end{array}$ & $\begin{array}{c}\text { Austrália } \\
41 \text { mil t } \\
0,7 \%\end{array}$ & $\begin{array}{c}\text { Austrália } \\
37 \text { mil t } \\
1 \%\end{array}$ \\
\hline & $\begin{array}{c}\text { Outros } \\
937 \text { mil t } \\
20 \% \\
\end{array}$ & $\begin{array}{c}\text { Outros } \\
105 \text { mil t } \\
5 \% \\
\end{array}$ & $\begin{array}{c}\text { Outros } \\
81 \text { mil t } \\
3 \%\end{array}$ & $\begin{array}{c}\text { Outros } \\
100 \text { mil t } \\
2 \% \\
\end{array}$ & $\begin{array}{c}\text { Outros } \\
106 \text { mil t } \\
2 \% \\
\end{array}$ & $\begin{array}{c}\text { Outros } \\
137 \text { mil t } \\
2 \% \\
\end{array}$ \\
\hline Total & 4556 mil t & 2260 mil t & 3085 mil t & 4990 mil t & 6032 mil t & 6827 mil t \\
\hline
\end{tabular}

Fonte: elaborado pelos autores (2016).

Em 1990 o principal exportador mundial de carne suína era a Holanda (23\%), seguido pela Dinamarca (19\%), Bélgica (8\%), Alemanha (8\%), Canadá (7\%), China (5\%), Taiwan (5\%) e Hungria (5\%), os outros países do mundo eram responsáveis por $(21 \%)$.

Ao comparar 1995 e 1990, notam-se grandes mudanças no cenário mundial. Com a criação da União Europeia em 1993, os países que eram os mais importantes na exportação de carne suína em 1990 (Holanda, Dinamarca, Bélgica e Alemanha) passaram a integrar o bloco, assim, em 1995, a União Europeia aparece como o maior exportador (34\%). Além disso, as exportações caíram de 4.556 mil toneladas para 2.260 mil toneladas, uma redução de $50 \%$, esse fato pode ser explicado pela criação do bloco, já que os países membro possuem livre comércio 
entre si, passando a contabilizar apenas as exportações para fora do bloco. Neste mesmo ano, Taiwan (17\%) passou a ser o segundo maior exportador, seguido por, Canadá (16\%), Estados Unidos (16\%), China e Polônia (5\%), Hungria (4\%), Brasil (2\%), Cazaquistão (2\%) e outros países $(5 \%)$.

No ano 2000, fica mais evidente a concentração de mercado, quando os três maiores, União Europeia, Canadá e Estados Unidos, foram responsáveis por $82 \%$ das exportações mundiais. O Brasil (5\%) passou a ser mais representativo, triplicando as suas exportações em relação à 1995 e tornou-se o quarto maior exportador, seguido por, China (5\%), México (2\%), Austrália (2\%), Coréia do Sul (1\%) e outros países (3\%).

Em 2005 os Estados Unidos (24\%) dobraram as suas exportações, ultrapassando a União Europeia (22\%), que teve uma pequena retração. O Canadá (22\%) também aumentou significativamente as suas exportações, tornando a paridade maior entre os três principais exportadores. O Brasil (15\%), quadriplicou as suas exportações, consolidando-se como um grande exportador de carne suína. Os outros países principais foram China (10\%), Chile (3\%), México (1\%) e Austrália (1\%).

Em 2010, os Estados Unidos (32\%) e a União Europeia (28\%), continuaram aumentando as suas exportações, o Canadá (19\%) teve um pequeno aumento, mas perdeu um pouco da participação, o Brasil (10\%) manteve a quarta posição, porém, perdeu participação e diminuiu a quantidade exportada, a China (5\%), teve uma retração de $45 \%$ nas exportações. O Chile (2\%), México (1\%) e Austrália $(0,7 \%)$ mantiveram as suas posições.

Em 2014 os oito países principais continuavam os mesmos que em 2005, com aumento nas exportações dos Estados Unidos (32\%), da União Europeia (31\%) e do Canadá (18\%). O Brasil (8\%) teve outra quantidade exportada, porém, manteve a posição. A China (4\%), o Chile (2\%), o México (2\%) e a Austrália (1\%) tiveram poucas alterações.

É possível perceber que há alta concentração de mercado, visto que, os primeiros quatro países são responsáveis por mais de $50 \%$ das exportações. Entretanto, ao comparar o ano de 1990 e o de 2014, percebe-se que no primeiro, as exportações contavam com a participação de um maior número de players, pois, os oito principais países, eram responsáveis por $80 \%$ das exportações, restando ainda $20 \%$, onde os responsáveis eram países com uma menor representatividade individual, enquanto em 2014, os principais países representavam $98 \%$ das exportações, restando apenas $2 \%$, em que os responsáveis foram outros países. 


\section{METODOLOGIA}

Nesta seção são apresentadas a metodologia utilizada para a realização deste trabalho, dividida em duas partes. Na primeira, é apresentado o método do $C M S$, e na segunda, os procedimentos operacionais.

\subsection{Constant Market Share}

O CMS utilizado neste trabalho pode ser expresso pela seguinte equação:

$$
\sum_{j=i}^{n}\left(E_{j}^{\prime}-E_{j}\right)=\sum_{j=i}^{n}\left(r E_{j}\right)+\sum_{j=i}^{n}\left(r_{j}-r\right) E_{j}+\sum_{j=i}^{n}\left(E_{j}^{\prime}-E_{j}-r_{j} E_{j}\right)
$$

(c)

em que $E_{j}^{\prime}$ representa o valor das exportações de carne suína do país em foco para o mercado j, no período 2;

$E_{j}$ é o valor das exportações de carne suína do país em foco para o mercado j, no período 1;

$E_{j}^{\prime}-E_{j}$ é o crescimento efetivo do valor das exportações de carne suína do país em foco para o mercado j;

$r$ representa o percentual de crescimento do valor das exportações mundiais de carne suína, do período 1 para o período 2;

$r_{j}$ é a porcentagem de crescimento do valor das exportações mundiais de carne suína para o mercado j, do período 1 para o período 2; e

$n$ é o número de mercados.

O desempenho do país no comércio internacional de carne suína será decomposto em três efeitos:

a) Efeito do crescimento do comércio mundial $\sum_{j=i}^{n}\left(r E_{j}\right)$ : representa o crescimento porcentual que seria observado caso as exportações do país crescessem na mesma proporção que o comércio mundial. Esse efeito indica a expansão dos mercados-alvo, portanto é um fator exógeno;

b) Efeito destino das exportações $\left.\sum_{j=i}^{n}\left(r_{j}-r\right) E_{j}\right)$ : representa os ganhos ou perdas, em termos da porcentagem de crescimento, em razão do fato de as funções das exportações serem direcionadas a países que cresceram a taxas superiores ou inferiores a média geral; 
c) Efeito competitividade $\sum_{j=i}^{n}\left(E_{j}^{\prime}-E_{j}-r_{j} E_{j}\right)$ : representa a porcentagem do crescimento ou perda de participação do produto nos diferentes mercados, em razão da competitividade do produto, podendo ser em termos de preços e, ou custos, ou ainda, em virtude de melhorias na qualidade do produto, processos tecnológicos ou melhoria nas condições de financiamento. Esse é um efeito endógeno, pois são determinados os fatores internos da nação.

Apesar de amplamente utilizado em trabalhos que analisam a competitividade, o modelo Constant Market Share não está isento de limitações. Pode-se citar, entre eles, o fato do modelo identificar se houve ganho ou perda de competitividade, mas não estabelecer relações diretas de causalidade, ou seja, não explica quais foram os fatores geradores (ALMEIDA; SILVA; ANGELO, 2012) . Entretanto, o modelo pode servir de ferramenta para direcionar o setor exportador à mercados mais favoráveis (CARVALHO, 1995).

\subsection{Procedimentos operacionais}

As fontes que serviram de base para a aplicação da metodologia foram o Sistema de Análise das Informações de Comércio Exterior via Web (ALICEWEB), do Ministério do Desenvolvimento, Indústria e Comércio Exterior (MDIC) e o United States Department of Agricultura (USDA). No primeiro foram obtidos os dados das exportações brasileiras de carne suína, e no segundo, os dados das exportações dos Estados Unidos e do mundo.

O período de análise foi de 1990 a 2014, abrangendo desde a solidificação da abertura comercial brasileira até o momento atual.

Para que o método CMS capte com maior precisão as mudanças ocorridas ao longo do tempo, deve-se utilizar períodos menores que o proposto neste estudo, assim, conforme sugerido por Milana (1988), dividiu-se o período de 1990-2014 em cinco subperíodos: 19901993; 1994-1998; 1999-2002; 2003-2008; 2009-2014.

O primeiro subperíodo (1990-1993), representando a consolidação da abertura comercial brasileira. No segundo subperíodo (1994-1998), houve implantação do Plano Real, a troca de regime cambial e a estabilização da economia brasileira. O terceiro subperíodo (19992002), justificado pela nova troca de regime cambial em 1999, além, do significante incremento que as exportações de carne suína do Brasil e dos Estados Unidos no período. O quarto subperíodo (2003-2008), houve a consolidação das exportações brasileiras. O quinto e último subperíodo (2009-2014), representando a situação atual.

\begin{tabular}{lr}
\hline Volume 5, Número 9 & Revista UNEMAT de Contabilidade \\
Jan./Jul. 2016 & ISSN: 2316-8072
\end{tabular}




\section{ANÁLISE E DISCUSSÃO DOS RESULTADOS}

Nessa seção serão apresentados os resultados do Constant Market Share em três efeitos, comércio mundial, destino e competividade.

\section{Período de 1990-1993}

Em 1990 as exportações mundiais de carne suína foram de 4.556 mil toneladas, e em 1993 foram de 2.251 mil toneladas, um decréscimo de 2.490 mil toneladas ou 55,49\%. Esse decréscimo expressivo no comércio mundial é justificado pela já referida criação do bloco União Europeia.

O Brasil exportou 12,49 mil toneladas em 1990, e em 1993 o país exportou 43,74 mil toneladas, um crescimento efetivo de 31,25 mil toneladas ou 250,25\%. Como indicado pela retração nas exportações mundiais, o efeito comércio mundial apresentou resultado negativo $(22,17 \%)$. O grande responsável pelo bom desempenho das exportações brasileiras no período foi o efeito competitividade, apresentando valor positivo (113,96\%). O efeito destino, ainda que em menor proporção, também colaborou para o resultado do período, apresentando valor positivo $(8,21 \%)$.

Os Estados Unidos exportaram em 1990, cerca de 158 mil toneladas e 202 mil toneladas em 1993, apresentando um crescimento de 44 mil toneladas ou 27,85\%. O efeito comércio mundial apresentou valor negativo $(208,61 \%)$, indicando que se o país tivesse seguido a mesma taxa de crescimento que o resto do mundo, as suas exportações teriam diminuído 91,78 mil toneladas. O efeito destino apresentou valor positivo $(119,86 \%)$, e se as suas exportações tivessem crescido na mesma taxa que o seu mercado importador cresceu, o aumento em suas exportações teria sido de 52,74 mil toneladas. O efeito competitividade também se mostrou positivo $(188,75 \%)$, indicando que se as exportações tivessem crescido na mesma proporção, o país teria exportado 83,05 mil toneladas a mais.

O efeito competividade se mostrou o principal responsável pelo crescimento das exportações de ambos os países. Para o Brasil, um fato que contribuiu para o aumento da competitividade foi a abertura comercial no início da década de 1990, que foi muito importante para a suinocultura, pois, com as novas leis de importação o setor pôde fazer os incrementos tecnológicos necessários, gerando um aumentando no uso de inseminação artificial, no controle preventivo de doenças, bem como a divisão do sistema de produção (cria e recria, engorda). Nesse período a produção passou a crescer a uma taxa maior que o resto do mundo (EMBRAPA, [s.d.]; MELO, 2006). Para a competitividade dos Estados Unidos, a justificativa 
também está no avanço tecnológico, apesar de suas melhorias (genética, produção em escala e controle de doenças) terem iniciado uma década antes, em 1980, os seus efeitos continuaram na década de 1990. O estado da Carolina do Norte, por exemplo, através de melhoramento genético, conseguiu reduzir os custos de alimentação dos animais, passou a ser um dos maiores produtores do país (NATIONAL PORK BOARD, 2009).

\section{Período de 1994 a 1998}

Nesse período, as exportações mundiais voltaram a crescer, passando de 2.251 mil toneladas em 1994, para 2.955 mil toneladas em 1998, um acréscimo de 704 mil toneladas ou $31,27 \%$.

Em 1994, o Brasil exportou 33,99 mil toneladas, e em 1998, 73,02 mil toneladas, apresentando um crescimento efetivo de 39,02 mil toneladas ou 114,78\%. Nesse período, o efeito comércio mundial apresentou valor positivo (26,13\%), indicando que se o Brasil tivesse aumentado as suas exportações na mesma intensidade que as exportações mundiais, o aumento em suas exportações teria sido de 50,70 mil toneladas. $\mathrm{O}$ efeito destino apresentou valor positivo $(1.589,02 \%)$, indicando que o país exportou para mercados onde a importação teve grande expansão, mostrando-se responsável pelo bom desempenho no período. Entretanto o efeito competitividade teve valor negativo $(1.515,15 \%)$, indicando que o país não foi competitivo o suficiente para suprir as necessidades dos mercados destinos e ampliar ainda mais a sua participação no montante importado por esses países.

Durante a década de 60 e 70 a agropecuária brasileira, através de crédito fácil e juros subsidiados, cresceu a taxas mais elevadas que os outros setores. Entretanto, com o país enfrentando uma crise econômica durante o final da década de 80 e início de 90, o governo deixou de ser o maior financiador do meio rural, o que acarretou em redução do crédito disponível e aumento das taxas de juros real. Além do crédito ter ficado mais difícil, a discrepância entre a correção dos preços mínimos e dos saldos devedores dos financiamentos, corroborou para o endividamento do setor. E apesar das tentativas do governo de minimizar esse problema, refinanciando e perdoando dívidas, a implementação do Plano Real, a sobrevalorização da moeda até o final de 1998, e a redução das tarifas de importação de produtos agrícolas, fizeram com que a agropecuária do país passe por um período de crise, sendo esta, uma das possíveis explicações para a suinocultura brasileira não ter aproveitado totalmente as oportunidades de crescimento do período (EMBRAPA, 2010; GROSSI; SILVA, 2008; SANTIAGO; SILVA, 1999). 
Os Estados Unidos exportaram 249 mil toneladas em 1994, e 558 mil toneladas em 1998, um crescimento efetivo de 309 mil toneladas ou 124,09\%. O efeito comércio mundial apresentou valor positivo (15,90\%), sendo responsável pelo acréscimo de 49,128 mil toneladas, nas exportações do país. O efeito destino também apresentou valor positivo (28,92\%), indicando que o crescimento das importações nos mercados destino foram responsáveis pelo aumento de 89,364 mil toneladas nas exportações. E por último o efeito competitividade, também com valores positivos $(55,18)$ mostrou-se o maior responsável pelo bom desempenho no período, corroborando com 170,507 mil toneladas no total exportado.

\section{Período 1999-2002}

Nesse período, as exportações mundiais foram de 3.247 mil toneladas em 1999 e 3.727 mil toneladas em 2002, um acréscimo de 480 mil toneladas ou 14,78\%.

Em 1999, o Brasil havia exportado 75,41 mil toneladas, e em 2002, o país mostrou um importante acréscimo em suas exportações, com um total de 449,21 mil toneladas, um crescimento efetivo de 373,8 mil toneladas ou $495,7 \%$. O efeito comércio mundial teve resultado positivo $(0,68 \%)$, mas pouco significativo, mostrando que se o Brasil tivesse seguido a mesma taxa de crescimento mundial, as suas exportações teriam aumentado em apenas 2,52 mil toneladas. O efeito destino apresentou resultado negativo $(4,81 \%)$, indicando que os principais mercados do Brasil tiveram retração nas importações. E o efeito competitividade apresentou-se positivo $(104,14 \%)$ e o responsável pelo bom desempenho do Brasil no período.

Esse foi o período em que a suinocultura do Brasil mais cresceu, o bom preço da carne, e os aumentos nas exportações, fizeram com que o rebanho nacional crescesse. No entanto, em 2002 o preço dos insumos, principalmente do milho, gerou um aumento no custo de produção, e em conjunto com a redução da demanda, resultou em excesso de oferta no mercado nacional, e consequentemente, na queda dos preços. Esse fato, fez a suinocultura brasileira passar por uma grande crise nos anos de 2002 e 2003 (MOURA; LÍRIO; SILVA JUNIOR, 2005).

Os Estados Unidos tiveram nesse período o seu maior incremento, passando de $582 \mathrm{mil}$ toneladas em 1999, para 1.425 mil toneladas em 2002, um acréscimo de 144,84\%. Novamente todos os efeitos tiveram valores positivos, colaborando com o bom desempenho do país. O efeito comércio mundial apresentou uma taxa de 8,57\%, contribuindo com um acréscimo de 72,285 mil toneladas, o efeito destino 12,03\%, contribuindo com 101,436 mil toneladas, e mais uma vez o efeito competitividade $(79,39 \%)$ foi o responsável pela maior parte do acréscimo nas exportações, contribuindo com 669,277 mil toneladas exportadas. 
Para os Estados Unidos, a década de 1990 foi um período de mudança na estrutura produtiva, enquanto a produção de suínos crescia a uma média de $1 \%$ ao ano, o número de produtores decrescia a $7 \%$ ao ano, sugerindo que o país estava se especializando, os pequenos produtores estavam saindo do negócio, e o resultado foram fazendas produtoras com três vezes mais animais no início do ano 2000. Dessa forma, a economia gerada pela produção em escala e especialização foram os responsáveis pelo bom resultado do período (OECD, 2003).

\section{Período 2003-2008}

Nesse período, as exportações mundiais de carne suína foram de 4.164 mil toneladas em 2003 e 6.170 mil toneladas em 2008, um crescimento de 2.006 mil toneladas ou 48,17\%.

O Brasil exportou 458,03 mil toneladas em 2003 e 467,55 mil toneladas em 2008, um crescimento efetivo de 9.513 mil toneladas ou 2,08\%. O Efeito comércio mundial teve valor positivo $(2.593 \%)$, indicando que se as exportações brasileiras tivessem crescido na mesma proporção que as exportações mundiais o país teria aumentado as suas exportações em 246,75 mil toneladas. O efeito destino também apresentou resultado positivo $(1.212,04 \%)$, mostrando que se se as exportações do Brasil tivessem seguido a taxa de crescimento dos seus principais destinos o país teria aumentado as suas exportações em 115,31 mil toneladas. Já o efeito competitividade apresentou valor negativo (3.705,66\%), indicando que o crescimento do comércio mundial e dos seus principais destinos foram os responsáveis por seu crescimento efetivo e não a sua competitividade.

A crise iniciada no ano 2002 agravou-se ainda mais com a restrição Russa sobre a carne Catarinense, estado esse, que era responsável por cerca de $75 \%$ das exportações brasileiras para aquele país, o que levou ao abate de 300 mil matrizes e um prejuízo de US\$ 200 milhões. Além disso, o surgimento de casos de febre aftosa no Mato Grosso do Sul fez com que vários mercados fechassem as portas para a carne brasileira em outubro de 2005, com isso, em 2006, a carne suína teve uma redução de $15,5 \%$ do volume exportado, comparado ao ano anterior (ROCHA; MOURA; GIROTTO, 2007; SUINOCULTURA INDUSTRIAL, 2003). Em 2008, a crise financeira mundial afetou as exportações brasileiras, justamente no período onde as suas vendas são maiores, o último trimestre (SUINOCULTURA INDUSTRIAL, 2009).

Os Estados Unidos exportaram em 2.110 mil toneladas em 2003 e 1.857 mil toneladas em 2008, um decréscimo de 253 mil toneladas ou $12 \%$. O efeito comércio mundial apresentou valor positivo (166\%), sugerindo que se o país tivesse tido a mesma taxa de crescimento que o resto do mundo ele teria aumentado as suas exportações em 420,75 mil toneladas. O efeito destino teve valor negativo (218\%), demonstrando que o mercado para o qual os Estados 
Unidos exportam tiveram uma retração nas suas importações, e que se o país tivesse obtido a mesma taxa de crescimento, as suas exportações teriam diminuído 552,149 mil toneladas. O efeito competitividade também apresentou valor negativo (48\%), entretanto, com um menor impacto, sugerindo uma redução de 121,604 mil toneladas nas exportações.

\section{Período 2009-2014}

Nesse período, que retrata a situação atual da suinocultura, as exportações mundiais foram de 5.633 mil toneladas em 2009, e em 6.997 mil toneladas em 2014, um acréscimo de 1.254 mil toneladas ou $22,26 \%$.

O Brasil exportou em 2009 um total de 529,19 mil toneladas, e 499,14 mil toneladas em 2014, um decréscimo de 30,04 mil toneladas nas suas exportações ou 5,68\%. O efeito comércio mundial foi positivo $(443,07 \%)$ indicando que se as exportações do Brasil tivessem crescido na mesma proporção que o resto do mundo, elas teriam crescido 133,14 mil toneladas. O efeito destino apresentou valores negativos $(2.002,08 \%)$, indicando que os principais mercados da carne brasileira tiveram retração nas importações e se o país tivesse seguido a taxa de crescimento deles, o país teria diminuído as suas exportações em 661,96 mil toneladas, uma quantidade maior que a exportada no início do período. Entretanto, o efeito competitividade mostrou-se positivo $(1.659,91 \%)$, indicando que a carne suína brasileira é competitiva, e esse efeito em conjunto com o efeito comércio mundial foi o responsável por manter as exportações do país, não deixando que elas caíssem ainda mais.

Nesse período as exportações estadunidenses tiveram novo incremento, passando de 1.915 mil toneladas em 2009, para 2.204 mil toneladas em 2014, um aumento de 289 mil toneladas ou 15, 09\%. O efeito comércio mundial apresentou valor positivo (159\%), demonstrando que se o país tivesse aumentado as suas exportações na mesma proporção que o resto do mundo, o incremento seria de 459,985 mil toneladas. O efeito destino apresentou valores negativos (224\%), indicando que se o país tivesse tido a mesma taxa de crescimento que seus destinos, as suas exportações teriam sofrido uma redução de 648,636 mil toneladas. O efeito competitividade apresentou um valor positivo (165\%), o que representa um acréscimo de 477,651 mil toneladas nas exportações, e junto com o efeito comércio mundial, foi responsável por manter as exportações do país em ascensão.

Apesar de ter apresentado bons resultados, os Estados Unidos, passaram por duas crises no período, a primeira, provocada pelo surto de "gripe suína", e após perceberem 
o impacto na suinocultura as autoridades passaram a chamar a doença de gripe H1N1, no entanto, diversos países (China, Rússia e Coréia do Sul) fizeram restrição total ou parcial à carne suína estadunidense (JOHNSON, 2009). A segunda crise foi em 2014, quando a Rússia voltou a embargar os produtos estadunidense por rações políticas.

No Brasil, a suinocultura passou em 2012 por uma crise semelhante a de 2002, a alta nos preços dos insumos (milho e soja) e a queda do preço no kilo do suíno fizeram com que muitos suinocultores abandonassem a atividade, resultando no abate de 360 mil matrizes (ROPPA, 2014). Já em 2014, o setor mostrou sinais de recuperação, com a redução preço dos insumos, e o aumento das exportações para a Rússia (COSTAS, 2014).

\section{CONSIDERAÇÕES FINAIS}

Nos três primeiros períodos (1990-1993, 1994-1998, 1999-2002) as exportações brasileiras cresceram a taxas mais elevadas que o restante do mundo, tendo sido, no terceiro, o crescimento mais representativo (495\%). No penúltimo período (2003-2008), as exportações se estabilizaram, apresentando uma taxa de crescimento de $2,08 \%$. No quinto e último período (2009-2014) as exportações caíram 6\%.

Os efeitos apresentados pelo CMS apontam que no primeiro e terceiro período a competitividade da carne suína brasileira foi o maior responsável pelo aumento das exportações. No segundo período, o responsável pelo bom desempenho foi o crescimento nas importações nos mercados destino da carne brasileira. No quarto e quinto período, tanto o comércio mundial quanto os destinos apresentaram resultados favoráveis ao aumento das exportações, enquanto a competitividade, apresentou taxas negativas e altas, $-3705 \%$ e $-1659 \%$, no quarto e quinto período, respectivamente.

Alguns acontecimentos foram apresentados para explicar a os resultados. A utilização de tecnologias a partir da década de 1990 mostrou-se muito importante para o setor, proporcionando aumento de escala e redução de custos. A sanidade animal, e não apenas dos suínos, como, também bovinos e frangos, interferem na imagem da carne suína brasileira no mercado internacional, tendo sido responsável por períodos de dificuldade, como em 2002. E a importância da ração no custo do produto faz com que o setor se torne dependente dos preços do milho e do soja para obter lucro satisfatório. 
Os Estados Unidos apresentaram crescimento em todos os períodos, sendo o incremento mais significativo, assim como no Brasil, ocorrido no terceiro período (144\%). O efeito competitividade não foi o mais significativo apenas no quarto período, quando o efeito comércio mundial foi o responsável pelo crescimento das exportações. Apesar da quantidade exportada pelos Estados Unidos ser bem maior que a exportada pelo Brasil, o país apresenta as mesmas fragilidades, sanidade animal e custo dos insumos.

\section{AGRADECIMENTOS}

A pesquisa foi financiada pela Fundação de Amparo à Pesquisa de Mato Grosso (FAPEMAT). Contudo, a análise e os comentários são de responsabilidade dos autores.

\section{REFERÊNCIAS}

ALMEIDA, A. N. DE; SILVA, J. C. G. L. DA; ANGELO, H. Desempenho das exportações do Brasil e Canadá no mercado de madeira serrada de coníferas durante a crise do subprime. Scientia Forestalis, v. 40, n. 94, p. 267-277, 2012.

CARVALHO, F. M. A. O comportamento das exportações brasileiras e a dinâmica do complexo agroindustrial. [s.1.] Tese (Doutorado em Economia Aplicada) -- Escola Superior de Agricultura Luiz Queiroz, Universidade de São Paulo, São Paulo, 1995.

COSTAS, R. Resultado de embargo russo divide exportadores no Brasil. Disponível em: <http://www.bbc.com/portuguese/noticias/2014/12/141209_russia_ru>. Acesso em: 26 ago. 2015.

EMBRAPA. A suinocultura no Brasil. Disponível em:

$<$ http://www.cnpsa.embrapa.br/cias/index.php?option=com_content\&view=article\&id=5:orig em-dos-suinos\&catid=4:suinos-publico\&Itemid=19>. Acesso em: 1 ago. 2015.

EMBRAPA. Evolução da política de crédito rural brasileira. Disponível em: <www.cpac.embrapa.br/download/1911/t>. Acesso em: 24 ago. 2015.

GROSSI, M. E. DEL; SILVA, J. G. DA. As (re)negociações das dívidas agrícolas. Sociedade e desenvolvimento rural, v. 2, n. 1, p. 203-212, 2008.

JOHNSON, R. Potential farm sector effects of 2009 H1N1 "swine flu": questions and answers. Disponível em: 〈https://www.fas.org/sgp/crs/misc/R40575.pdf>. Acesso em: 25 fev. 2016.

MELO, G. B. DE. Produtos congelados são a locomotiva das exportações de carne suína. Disponível em: <http://www.cepea.esalq.usp.br/pdf/Cepea_ExportacaoCarneSuina.pdf $>$. Acesso em: 24 ago. 2015.

MILANA, C. Constant market shares analysis and index number theory. European Journal of Political Economy, v. 4, n. 4, p. 453-478, 1988.

MOURA, A D.; LÍRIO, V. S.; SILVA JUNIOR, A. G. Diagnóstico da cadeia produtiva da suinocultura da região de Pará de Minas - MG. SEBRAE - MG, p. 96, 2005.

NATIONAL PORK BOARD. Quick facts - the pork industry at a glance. Disponível em: <https://www.pork.org/publications/2009-annual-report/>. Acesso em: 1 ago. 2015. 
OECD. Agriculture, trade and the environment -the pig sector. Paris: OECD Publishing, 2003.

ROCHA, D. T.; MOURA, A D.; GIROTTO, A F. Análise de risco de sistemas de produção de suínos, integrado e independente, em períodos de alta e baixa rentabilidade. Revista de Economia e Agronegócio, v. 5, n. 3, p. 401-424, 2007.

ROPPA, L. A crise da suinocultura brasileira. Disponível em:

<http://www.emater.go.gov.br/w/4307>. Acesso em: 26 ago. 2015.

SANTIAGO, M. M. D.; SILVA, V. DA. A política de crédito rural brasileira e o endividamento do setor agrícola: antecedentes e desdobramentos recentes. Agricultura em São Paulo, v. 46, p. 47-69, 1999.

SUINOCULTURA INDUSTRIAL. Suinocultura atravessa pior crise. Disponível em: $<$ http://www.suinoculturaindustrial.com.br/noticia/suinocultura-atravessa-piorcrise/20030526093303_04632>. Acesso em: 15 ago. 2015.

SUINOCULTURA INDUSTRIAL. Exportações de carne suína. Disponível em: <http://www.suinoculturaindustrial.com.br/noticia/exportacoes-de-carnesuina/20090416081338_X_736>. Acesso em: 25 ago. 2015.

USDA. Global Agricultural Trade System online. Disponível em:

<http://apps.fas.usda.gov/gats/ExpressQuery1.aspx>. Acesso em: 1 maio. 2015. 